\title{
FERIMENTO PUNTIFORME EM TÓRAX PRODUZINDO LESÃO CARDÍACA
}

\section{PUNCTIFORM THORACIC WOUND PRODUCING CARDIAC LESION}

\author{
Fernando Antônio Campelo Spencer Netto, TCBC-PE ${ }^{1}$ \\ Paulo Ricardo Camelo Vasconcelos ${ }^{2}$ \\ Joma Magaly Cintra Pinto ${ }^{3}$
}

\section{INTRODUÇÃO}

Lesões puntiformes ou perfurantes são causadas por instrumentos alongados, finos e pontiagudos com diâmetro transverso reduzido. Por estas características, o instrumento usualmente afasta as fibras do tecido lesado, preservando-as de secção. São lesões de abertura estreita, com raro sangramento e aspecto aparentemente pouco nocivo à superfície corporal, podendo resultar em graves ferimentos em órgãos profundos como o coração ${ }^{3}$.

$\mathrm{O}$ presente artigo relata caso de feridas puntiformes toracoabdominais por instrumento manufaturado resultando em trauma penetrante cardíaco.

\section{RELATO DO CASO}

J.R.J., 17 anos, procedente de instituto para recuperação de adolescentes em Paulista - PE, foi admitido no Hospital da Restauração, apresentando escoriações lineares e feridas puntiformes em face anterior do tórax e abdome por instrumento puntiforme manufaturado "chuço", equimose cervical por tentativa de esganadura, hematoma em região parietal direita (Figura 1). No momento queixava-se de dor torácica e dificuldade respiratória.

Ao exame apresentava-se orientado, taquicárdico, com pletora de face, engurgitamento jugular, pulsos firmes. À ausculta o murmúrio vesicular preservado bilateralmente com hipofonese de bulhas. Abdome depressível e indolor.

Realizada telerradiografia de tórax que revelou alargamento de mediastino, particularmente em porção superior (Figura 2).

Indicada exploração cirúrgica, iniciou-se o procedimento com toracotomia anterolateral esquerda, com achado de hemopericárdio. Realizada pericardiotomia e retirados os coágulos, identificaram-se dois ferimentos puntiformes com sangramento ativo em ventrículo direito, os quais foram sutu-

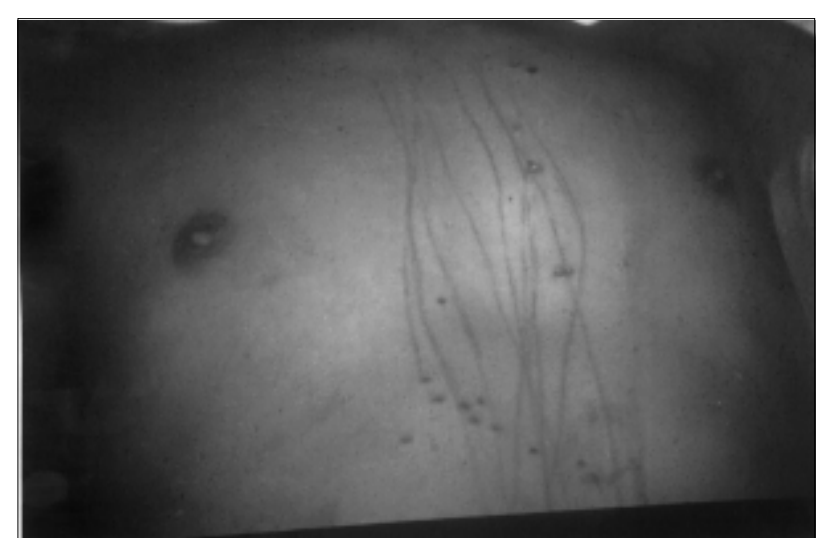

Figura 1 - Escoriações lineares e feridas puntiformes em face anterior do tórax e abdome por instrumento puntiforme manufaturado ("chuço").

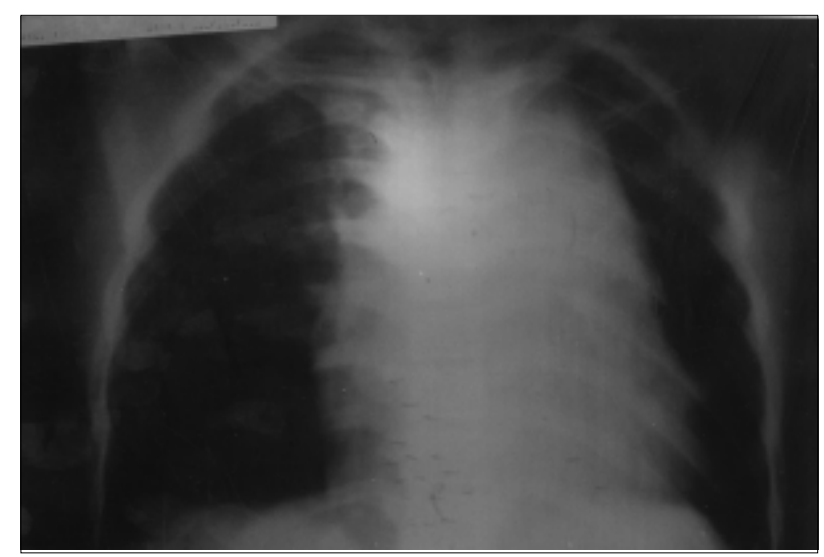

Figura 2 - Radiografia de tórax demonstrando alargamento de mediastino, particularmente em porção superior.

1. Cirurgião Geral da Emergência do Hospital da Restauração.

2. Residente de Cirurgia Vascular do Hospital da Restauração.

3. Acadêmica de Medicina do Hospital da Restauração.

Recebido em 28/1/2000

Aceito para publicação em 26/9/2000

Estudo desenvolvido na Emergência de Adultos do Hospital da Restauração - Recife - PE. 
rados. Optou-se por extensão da incisão ao hemitórax direito a fim de abordar hematoma de mediastino superior que correspondia a hematoma em timo, sendo feita a retirada deste. Devido à presença de feridas puntiformes em projeção abdominal, foi realizada laparotomia, sem achados.

Durante procedimento operatório o paciente manteve parâmetros vitais estáveis, com discreta hipotensão e bradicardia durante manipulação a fim de realizar a sutura cardíaca. Paciente encaminhado à Unidade de Terapia Intensiva, manteve-se estável, sendo extubado no segundo dia de pós-operatório, e retirados os drenos torácicos dois dias após. Ao quarto dia do pós-operatório foi detectada infecção superficial em sítio cirúrgico torácico, sendo tratada a infecção com curativos, evoluindo de forma satisfatória..

Evoluiu sem outras intercorrências, recebendo alta para a instituição de origem no 14ํㅜ dia pós-operatório.

\section{DISCUSSÃO}

O trauma torácico é a segunda causa de mortalidade por trauma nas populações adulta e pediátrica, sendo notada a crescente incidência de ferimentos penetrantes de tórax entre crianças e adolescentes ${ }^{2,4}$.

As feridas penetrantes do coração por arma branca são consideradas de melhor prognóstico que as produzidas por projéteis de arma de fogo, encerrando menor mortalidade e constituindo a maior parte dos pacientes que chegam a receber atendimento médico. Produzem lesões lineares ou puntiformes, usualmente em ventrículo direito, uma vez que ao penetrarem pela parede anterior do tórax geralmente lesam apenas aquela cavidade, como se observa neste caso. Os projéteis de arma de fogo produzem lesões de maior complexidade, acometendo mais de uma câmara, originando lesões irregulares na parede ventricular, favorecendo sangramento para cavidade torácica ${ }^{1,4,5}$.
O paciente estudado apresentava sinais clínicos de tamponamento cardíaco, sendo a hipótese corroborada pela radiografia de tórax, condições que motivaram a indicação cirúrgica. A ultra-sonografia ou a ecocardiografia são o "padrão-ouro" para o diagnóstico de derrames pericárdicos, porém nem sempre são disponíveis em serviços de urgência com a rapidez desejada ou em tempo integral ${ }^{5}$.

O tamponamento cardíaco, a despeito de causar efeitos deletérios à circulação (que podem levar ao óbito), exerce efeito protetor na lesão penetrante de coração, evitando a perda de sangue para a cavidade torácica ou meio externo, impedindo, assim, a hipovolemia e ocasionando restrição da expansibilidade pulmonar devida ao hemotórax ${ }^{1,5}$.

A presença de estabilidade hemodinâmica à admissão é relacionada a melhor prognóstico em pacientes com trauma de tórax e de coração. Coimbra, em estudo realizado em São Paulo, confirmou a relação entre índice anatômico da lesão e a gravidade em trauma penetrante de coração, encontrando diferença estatisticamente significativa entre sobreviventes e pacientes que foram a óbito ${ }^{2}$. O paciente em estudo apresentou baixos índices de gravidade, correlacionados a prognóstico favorável como constatado em sua evolução.

O caso apresentado demonstra um ferimento não usual, em que o instrumento agressor produziu uma lesão puntiforme que resultou em ferida cardíaca. $\mathrm{O}$ aspecto "inocente" da ferida cutânea poderia levar à desvalorização do quadro clínico do paciente, compatível com tamponamento cardíaco, e conseqüentemente à falha diagnóstica da grave lesão subjacente da qual o mesmo era portador ${ }^{3}$.

Formulada a hipótese de lesão cardíaca, o paciente foi conduzido para toracotomia exploradora onde se evidenciou o hemopericárdio e duas lesões em ventrículo direito. A abordagem cirúrgica de urgência mantém-se como método mais seguro para confirmação diagnóstica, permitindo o concomitante tratamento das lesões nos pacientes com traumatismo cardíaco penetrante.

\begin{abstract}
We report a case of a 17-year-old man with punctiforms thoracic and abdominal wounds. Clinical examination showed signs of cardiac tamponade. Roentgenogram demonstrated widened mediastinum and thoracotomy confirmed cardiac wound. We analyse the unusual trauma agent and prognostic factors in cardiac trauma. Wounds with "innocent" aspect can cause fatal lesions.
\end{abstract}

Key Words: Punctiform wound; Cardiac trauma.

\section{REFERÊNCIAS}

1. Arreola-Risa C, Rhee P, Boyle EM, et al.. Factors influencing outcome in stab wounds of the heart. Am. J. Surg. 1995;169:553-556.

2. Coimbra R, Pinto MCC, Razuk A, et al.. Penetrating cardiac wounds: predictive value of trauma indices and the necessity of terminology standardization. Am. Surg. 1995; 61:448-452, 1995.

3. França GV. Medicina Legal. Quarta edição. Rio de Janeiro. Ed. Guanabara Koogan, 1995.

4. Henderson VJ, Smith RS, Fry WR, et al.. Cardiac injuries: analysis of an unselected series of 251 cases. J. Trauma 1994;36:341-348.
5. Moreno C, Moore EE, Majure JA, et al.. Pericardial tamponade: a critical determinant for survival following penetrating cardiac wounds. J. Trauma 1986;26:821825.

Endereço para Correspondência

Dr. Fernando Antônio Spencer Netto

Rua Fernando Simões Barbosa, 50/102

51020-390 - Recife - PE

E-mail: kummer@netpe.com.br 